\title{
Analysis of usability evaluation according to the quality standards
}

\section{Análisis de evaluación de usabilidad de acuerdo con las normas de calidad}

AHUMADA-CERVANTES, María de los Ángeles †*, MELO-MORÍN, Julia Patricia and ÁLVAREZBALTIERRA, Eric

Instituto Tecnológico Superior de Pánuco, Computer Engineering Studies Division, Mexico.

ID $1^{\text {st }}$ Author: María de los Ángeles, Ahumada-Cervantes / ORC ID: 0000-0001-8164-2889, Publons ID: ABE-2558-2020, CVU CONACYT ID: 825136

ID $1^{\text {st }}$ Co-author: Julia Patricia, Melo-Morín / ORC ID: 0000-0001-7145-2344, Thomson ID Reseacher: I-3412-2018, Arxiv ID Author: 0000-0001-7145-2344, CVU CONACYT ID: 248185

ID $2^{\text {nd }}$ Co-author: Eric, Álvarez-Baltierra / ORC ID: 0000-0002-3444-5687, CVU CONACYT ID: 247114

\begin{abstract}
This research provides a study of usability as a quality attribute of Web pages, using as a benchmark the requirements that must be followed under the International Organization for Standardization / International Electrotechnical Commission 25000. The methods used to carry out this process are studied, as well as the description of the aspects to be considered for evaluation thereof. It carried out a review of the literature on software tools for measuring the usability of Web pages and disadvantages. The methodology that can be used is determined to perform the corresponding evaluation process and the results are established using a practical case.
\end{abstract}

Usability, web page, Quality, Evaluation

\begin{abstract}
Resumen
La presente investigación proporciona un estudio de la usabilidad como atributo de calidad de las Páginas Web, tomando como punto de referencia las características que deben de cumplir conforme al estándar de la norma Organización Internacional de Normalización/Comisión Electrotécnica Internacional 25000. Se estudian los métodos que se utilizan para llevar a cabo dicho proceso, así como, se describen los aspectos que se van a considerar para realizar la evaluación de estos. Se lleva a cabo una revisión de la literatura sobre las herramientas de software para la medición de la usabilidad de las Páginas Web y los inconvenientes. Se determina la metodología que puede ser utilizada para realizar el proceso de evaluación correspondiente y se establecen los resultados mediante la utilización de un caso práctico.
\end{abstract}

Usabilidad, Páginas web, Calidad, Evaluación

Citation: AHUMADA-CERVANTES, María de los Ángeles, MELO-MORÍN, Julia Patricia and ÁLVAREZ-BALTIERRA, Eric. Analysis of usability evaluation according to the quality standards. Journal Computer Technology. 2020. 4-13:8-15.

\footnotetext{
* Correspondence to Author (Email: angeles.ahumada@itspanuco.edu.mx)

$\dagger$ Researcher contributing as first author
} 


\section{Introduction}

Currently, the acquisition of software from desktop, web, mobile or service applications is largely dependent on the level of quality achieved by each of them, for this reason all types of industries that want to be highly competitive in the field. National and international markets have increased the level of quality in their processes (Villegas, 2009). Software quality is the degree to which the software has certain attributes that it must meet. Specifically in the Software industry, several attributes have been defined when specifying the quality of a product. Which are: usability, reliability, security, performance, always looking for customer satisfaction (Kan, 2002). Among the quality attributes, one of those considered important is usability, which indicates the ease with which a user can use a Web Page (Enriquez, 2013).

Usability is a quality attribute which refers to the ease for the user to do a certain task, which adapts to the needs and satisfaction of the same (Len Bass, 2003). The usability evaluation process could yield results that lead to improvements in web page production. The usability evaluation is for the purpose of modifying and optimizing some aspects of web pages that are poorly designed.

There are organizations that have worked on the standardization of quality aspects in software such as the ISO (International Organization for Standardization), the IEEE (Institute of Electrical and Electronics Engineers, Inc.) and the IEC (International Electrotechnical Commission). These standards coincide in specifying usability as an attribute of quality, which is important for the user, making the software product attractive, learned, used under certain conditions and contexts of use. To achieve this objective, the ISO / IEC 25000 Standard was taken as a reference for the evaluation of this quality attribute.

The existing software tools for the evaluation of usability do not specifically consider the evaluation of this quality attribute. They evaluate the user interface considering only some aspects of usability but do not specifically focus on a quality standard.
In recent years the use of web pages to develop daily activities within companies has been increasing, it is necessary to create criteria that allow the evaluation of usability as a quality attribute of the same. Considering the end user as the main actor in the use of web pages.

This work focuses in a general way on establishing the criteria that must be considered to carry out the usability evaluation. It is carried out as follows: In section I. Introduction, it provides an induction to the subject. In section II. Usability, in which the meaning is described considering the opinion of various authors. Section III. ISO / IEC 25000 Quality Standards, which makes an analysis of the points that will be taken to measure usability as a quality attribute. Section IV. It analyzes the evaluation methods that various authors have used in their research for the evaluation of usability. In section V. Provides a study of the existing tools for the evaluation of usability and their drawbacks. Section VI. It establishes a methodology to carry out the Evaluation of the usability of the Web Pages. In section VII the results are established and finally in VIII. Conclusions and future work are established.

\section{Usability}

The International Organization for Standardization proposes two definitions regarding the usability of software:

ISO / IEC 9126 establishes that "Usability refers to the ability of a software to be understood, learned, used and be attractive to the user under specific conditions of use".

ISO / IEC 9241 mentions that "Usability is the effectiveness, efficiency and satisfaction with which a product allows specific objectives to be achieved by specific users in a specific context of use".

Jakob Nielsen defines usability in terms of five attributes: ease of learning, efficiency, memorability, errors, and satisfaction. Nielsen mentions that the importance of these attributes varies depending on the context and the end users (Enriquez, 2013). 
Usability can be defined according to ISO 25000 as the ability of the Software to be understood, learned, used and attractive to the user when used under certain conditions. For which the standard divides these characteristics into sub-characteristics such as:

Ability to recognize its adequacy.

Learning capacity.

Ability to be used.

Protection against user errors.

User interface aesthetics.

Accessibility.

In conclusion, it can be defined that usability is the ease of use that an object or artifact has for a certain user, with respect to the environment in which it operates (Standardization, 2020). This concept is applied to different environments and objects to measure the process that is carried out. In this case, it will be used to evaluate the usability of the web pages.

Regarding the usability of the software, it constitutes a quality attribute that is essential for its success, as determined by the International Quality Standards ISO / IEC 25000 that are mentioned in the following section.

\section{ISO / IEC 25000 quality standard}

A. Quality. One of the important factors currently in Software development is the quality of the product as mentioned in the standards together with the quality of the process.

The quality of a software product is the set of qualities that characterize it and determine its usefulness and existence against standards. An adequate balance should be proposed in factors such as efficiency, reliability, satisfaction, among others, which can be defined under two aspects (Heck, 2010):

1. Internal quality: Measurable from internal characteristics, such as source code.
2. External quality: Measurable in the behavior of the product evaluated by the end user, which is what will be considered for this study.

\section{B. Standard 25000}

In recent times the ISO / IEC 25000 family of standards has emerged, which establishes a manual for the use of a series of international standards called Software Product Quality Requirements and Evaluation (SQuaRE System and Software Quality Requirements and Evaluation) (Standardization, 2020).

The ISO / IEC 25000 standard establishes a series of guides that are based on ISO / IEC 9126 and ISO / IEC 14598. Its main functionality is to guide software development by specifying the requirements that must be met as well as evaluating quality attributes.

The ISO 25000 standard establishes three views in the quality study of a product; the internal view, the wedge considers the size, complexity of the code and that it complies with the established norms according to the objectoriented development methodology. On the other hand, the external view, analyzes the performance of a web page, the memory usage of a web application or the uptime. The one to be considered in this study is the view in use, which is responsible for making measurements regarding the efficiency and use of the end-user software, so that the software is productive when performing the tasks assigned.

One of the important quality factors mentioned is usability, since it is what determines the degree of user satisfaction and on this depends whether the software is used efficiently or not.

To carry out the evaluation, it is necessary to analyze the methods used to evaluate usability and determine which ones are going to be considered for carrying it out.

\section{Usability evaluation methods}

Methods are the steps used to measure the usability of a product such as web pages. They help the evaluator to perform the work more efficiently, because researchers have used them over the years and have obtained favorable results in this process.

AHUMADA-CERVANTES, María de los Ángeles, MELO MORÍN, Julia Patricia and ÁLVAREZ-BALTIERRA, Eric. Analysis of usability evaluation according to the quality standards. Journal Computer Technology. 2020 
The usability assessment methods can be divided into: inspection, inquiry, test (Mohd Naz'ri Mahrin, 2009), Semi-cognitive model and the Eye Tracking Technique.

Inspection: They are a set of methods based on the examination of the user interface of an application by experts. In this method, each evaluator performs a diagnosis of the interface based on a heuristic checklist created for this purpose. Later they meet to discuss the elements found in the interface, finally a report of the aspects found is prepared in a qualitative way.

The methods are the following: Heuristic evaluation, plural usability tour and cognitive tour, standards inspection.

Inquiry: It consists of analyzing the tastes of the users, dislikes, needs and identification of requirements. Which can be: Field observation, guided discussion groups, interviews and recording of uses.

Test: In this method, users work on tasks using the system or its prototype and evaluators analyze the results to see how the interface supports users with their tasks. Which can be: performance measures, thinking aloud (Thinking Aloud), constructive interaction, retrospective test, driver's method (Giraldo, 2011).

These are methods that focus on evaluating the efficiency and effectiveness of the system, that is, they evaluate the usability objectively.

Semi-cognitive model: This evaluation method understands the interface as a communication mechanism between the designer and the user. There are two models, the designer model, which is the creator's mental image of what he wants to build and how it should work, and the user model that explains how the system works (Scolari, 2001).

Eye tracking: It is a novel technique that allows to have proof of what point of the information system the user has been looking at at all times. This technique provides information on the difficulty of finding specific aspects of the interface and the time or number of elements analyzed before finding the appropriate element (Juan-Miguel López Gil, 2010).
To determine a tool that serves as a support to measure Usability as a quality attribute under the ISO / IEC 25000 Standard, it is necessary to make an analysis of the different software that performs this process. This study will allow to know the criteria that must be evaluated in order to serve as support so that companies can validate the level of usability of web pages.

\section{Software tools for evaluating website usability}

The selection of several tools that are used to carry out the usability evaluation was carried out, which are described below:

- WebSAT: Static Web analyzer tool, is a prototype tool that inspects the HTML composition of web pages to detect usability problems.

WebXm: is the main risk solution in order to verify the problems that impact the efficiency and compliance with the user of the websites. It is developed by an IBM company, called WatchFire (Benavides \& Aros, 2012). Automate the detection of some page defects such as: broken links, spelling errors, slow loading pages, the way of navigation, to help improve the usability of the website. Its main function is to evaluate the quality of websites from the perspective of usability, but it does not evaluate the quality of use.

- Drum (Diagnostic Recorder for Usability Measurement) is a software tool that enables computer-aided analysis. Helps video recording methods in task analysis. Automatically calculates work time (Macleod \& Rengger, 1998).

PROKUS. System to measure usability taking into consideration the ergonomic design of the user interface (Gert Zülch, 2000). 
CrazyEgg: It is an online computer program that tracks the clicks that users make on each component, this tool makes heat maps, identifying distracting elements, relevant areas or places that do not contain links where users interacting with the page clicked. The data is exported to Excel or database. Although clicks are tracked on a single page, they do not monitor the entire session, so it does not analyze the behavior of visits between various pages of the web application or at different times.

Page Analytics: It is used as a google browser extension, it uses metrics to analyze the web page to be studied, it results in what users see when they click on the different elements of the web page, providing which parts are most used by For its users, it is found on the internet for free, although it sometimes allows analysis of complete sessions to be carried out, the information it provides can be a bit confusing. Therefore, it is important when using it to define well the objectives you want to achieve, as well as the metrics that are going to be used, otherwise it can cause a lot of work in this regard.

UxCheck: It is based on the 10 principles of Heuristic evaluation of Jacob Nielsen (Nielsen, 1994). This is installed in the browser and in this way the user can interact with the page and see what elements do not comply with the principles, it also allows adding notes, taking screenshots. It is free and easy to use, it focuses mainly on web design, it does not allow to establish new evaluation criteria.

Site Checker: Its evaluation is based on the W3C Web Content Accessibility Guidelines (WCAG). Valid Html code, as well as it can evaluate other content such as dead links, hidden files, Java scripts, CSS, additional comments in the HTML code and the text relationship code on a Web Page (Macho, 2013).

\section{Disadvantages of usability evaluation tools}

Some disadvantages of the aforementioned tools can be observed, which are:

- WebSat: Does not evaluate dynamic pages.

- WebMX: Evaluates the usability and accessibility of a web page. However, in the accessibility assessment you can only assess the contrasting text and background color.

- DRUM AND PROKUS: These tools cannot find dead links and additional comments in the code in the internal quality assessment.

- CrazyEgg: This tool does not provide the results automatically, it transports them to a spreadsheet, where they will be interpreted by usability experts.

- Page Analytics: It does an analysis of the entire sessions, however, the great variety of data it produces is confusing.

- UxCheck: It only uses heuristics to evaluate usability.

Site Checker: Evaluates internal quality and external quality only focuses on user accessibility.

As can be seen, most of the works cited above focus on evaluating usability in terms of content, accessibility of web interfaces. Other tools only evaluate the heuristics established by Nielsen for usability evaluation. None of them specifically focuses on measuring usability according to the Quality Standards of the ISO / IEC 25000 Norms specifically. The following section establishes the Methodology to be used to carry out this process. 


\section{Methodology to carry out the usability evaluation}

To carry out the evaluation of usability as an attribute of quality, the criteria must be established, as well as the attributes that allow assessing each one of them so that the web pages allow compliance with International Standards as established by the Norm ISO / IEC 25000 in its section 25010 in addition to the ISO / IEC 25022-2016 Standard) that measures the quality in use in the usability section, which is derived from the ISO 9241-11 Standard, which contemplates the efficiency criteria, satisfaction and ease of use, as quality criteria that must be considered to evaluate software products such as web pages.

The evaluation will be carried out through the following steps:

The inspection method will be used in which it will be carried out by five usability experts according to the studies carried out by Nielsen (Nielsen, 1994), on the grounds that a greater number of evaluators reduces the benefit considerably, in addition to You should take into account that it is from different disciplines, such as three experts in Web page design and two people from the IT area specialized in graphic design and programming:

The measurement instrument will be through the evaluation of the characteristics, which will include the following aspects to be evaluated.

Communication: Measures the degree of interaction between the Web interface and the end user (CCOM).

Ease of Use: Measures the degree of User Satisfaction with the Web Interface (CFUSO).

Aesthetics: This criterion measures the aesthetic design of the user interface (CFES).

Operability: Measures the ability of the User Interface to fulfill a certain function (CO).

Ease of Understanding: Measures the ability of the User Interface to use its resources in particular tasks and conditions of use (CFCOM).
Efficiency: Measures the time taken to complete a task in the Web Interface (CEF).

Fault Tolerance: Measures the ability of the Web Interface to prevent errors and set error messages appropriately (CTF).

Documentation and help: Measures the ease offered by the Web Interface to provide help to the user when interacting with the Web Page (CDYA).

For each criterion, a series of attributes will be established, which are the ones that the evaluator will use to give a weight to each criterion.

It is proposed to create an automated tool that evaluates all types of Web Pages according to the 8 criteria established by the ISO / IEC Standard, as well as the metrics that correspond to each criterion to evaluate the usability of the same.

Once the Methodology of this research has been determined, the results obtained from the usability evaluation analysis are established.

\section{Results}

To carry out the application of the usability evaluation criteria, a case study was used, the page of the Higher Technological Institute of Pánuco, the quantification of the criteria was determined based on a liker scale from 0 to 5 , where The Value Judgment found in Table 1, goes from a total compliance to a Noncompliance.

\begin{tabular}{|l|l|}
\hline \multicolumn{1}{|c}{ Criterion } & Assigned value \\
\hline Fully complies & 5 \\
\hline Acceptably Compliant & 4 a 4.9 \\
\hline Comply regularly & 3 a 3.9 \\
\hline Satisfactorily complies & 1 a 2.9 \\
\hline Fails & 0.0 a 0.9 \\
\hline
\end{tabular}

Table 1 Rating scale Source: Self made

Subsequently, the total usability value of the Web Interfaces is obtained, which corresponds to the result of the sum of the scores of all the criteria as shown in equation 1 and equation 2 .

Criterion $=\Sigma$ (Attribute value) $/$ Non-total. (1)

AHUMADA-CERVANTES, María de los Ángeles, MELOMORÍN, Julia Patricia and ÁLVAREZ-BALTIERRA, Eric. Analysis of usability evaluation according to the quality standards. Journal Computer Technology. 2020 
Equation 2:

Usability level $=(\mathrm{CCOM}+\mathrm{CFUSO}+\mathrm{CFE}+\mathrm{COP}+\mathrm{CFCOM}+\mathrm{CEF}$ $+\mathrm{CTF}+\mathrm{CDOC}) /$ Total Criteria (2)

A rating will be determined on a scale from 0 to $100 \%$ as shown in Table 2.

\begin{tabular}{|l|l|r|}
\hline \multicolumn{1}{|c|}{ Criterion } & Abbreviation & Valuation\% \\
\hline $\begin{array}{l}\text { Communication } \\
\text { (content) }\end{array}$ & CCOM & $12.0 \%$ \\
\hline Easy to use & CFUSO & $15.0 \%$ \\
\hline Operability & COP & $13.5 \%$ \\
\hline Aesthetic factors & CFE & $12.0 \%$ \\
\hline $\begin{array}{l}\text { Ease } \\
\text { Understanding }\end{array}$ & CFCOM & $12.0 \%$ \\
\hline Efficiency & CEF & $12.5 \%$ \\
\hline Fault tolerance and & CTF & $12.5 \%$ \\
\hline $\begin{array}{l}\text { Documentation } \\
\text { help }\end{array}$ & CDYA & $10.5 \%$ \\
\hline
\end{tabular}

Table 2 Weighting of the Usability Evaluation Factors for web pages

Source: Self-made

The following equation 3 will be used, in which the value of the criterion will be determined, adding the value of each attribute established by the evaluator, between the total number, multiplied by the weighting of the factor.

Criterion $=\Sigma$ (attributes) $/$ Non-total $*$ weighting. (3)

Finally, to determine the usability rating, the sum of the 8 criteria is carried out by the weighting established for each criterion. In this way, the usability value granted to the evaluated web pages is obtained.

The technologies used for the development of the software for the evaluation of the usability of web pages that considers quality standards and evaluates each of the established criteria, is shown in Figure 1 below:

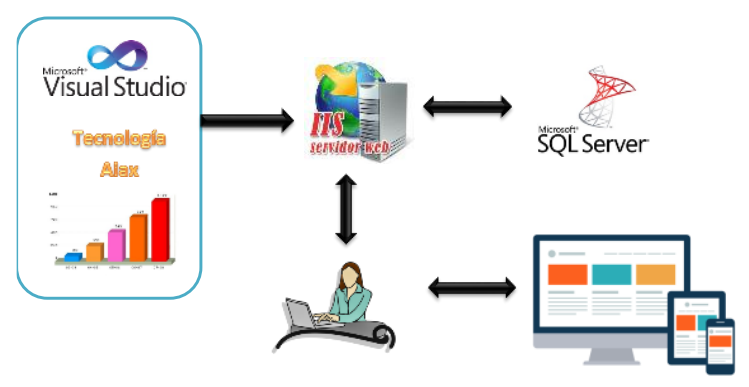

Figure 1 Evaluation Software Architecture Source: Self-made

ISSN: 2531-2197

ECORFAN® All rights reserved
It should be mentioned that the most objective result is presented by evaluation criteria, as shown in Figure 2, since it allows a clearer view of the evaluation results. The Software tool allows evaluating each of the 8 criteria. In this case, the operation of the web page to be studied is presented:

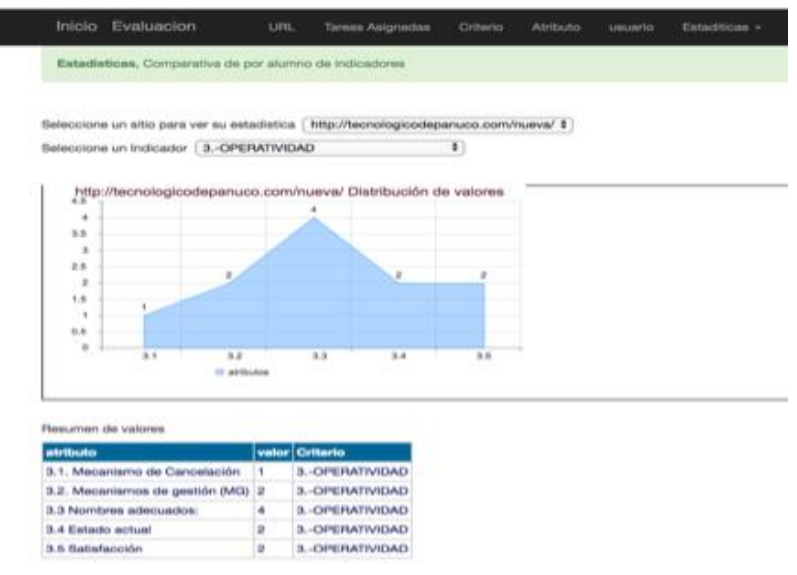

Figure 2 Operability

Source: Self-made

Regarding the results obtained in the operational criterion, it is observed in Figure 2 that point 3.1 management mechanisms, cancellation mechanisms, satisfaction, are below the average, because in the first instance the home page it does not allow you to configure the environment where you work and also according to the results it does not provide user satisfaction. In this way, the results of the 8 criteria established to evaluate the usability of the web pages are obtained, from communication to documentation and help of the web page.

\section{Conclusions}

The present research provides a study that serves to determine the criteria to carry out the usability evaluation as a quality attribute, taking the ISO / IEC 25000 standard to find aspects of the interface that are poorly designed and propose improvements to the web pages so that the end user achieves efficiency and satisfaction in using it. The growing need for companies to have web pages that are usable and comply with the quality standards established by international standards, makes it necessary to evaluate usability as a quality principle, in such a way that it allows software developers to realize account of what they must modify in the design of the web pages to improve their usability, as well as save time in maintenance, which translates into a cost reduction in coding hours.

AHUMADA-CERVANTES, María de los Ángeles, MELOMORÍN, Julia Patricia and ÁLVAREZ-BALTIERRA, Eric. Analysis of usability evaluation according to the quality standards. Journal Computer Technology. 2020 
As work in the future, it is intended to carry out an evaluation model of the usability of the Web Pages that includes an experimental group in which the results are analyzed using the software tool and the Eye tracking technique that allow obtaining the preferences of the users. users.

\section{References}

Len Bass, P. C. (2003). Software Architecture in Practice (tereca edición ed.). Pearson Education.

Benavides, E. S., \& Aros, C. G. (15 out of 06, 2012). Sistema difuso para la evaluación de la calidad externa de software orientado a la web. Revista de Educación de Ingeniería, 11.

Enriquez, J. a. (2013). Usabilidad en aplicaciones móviles. Informes Cientificos Tecnicos-unpa, 5.

Gert Zülch, S. S. (2000). Usability Evaluation of User Interfaces with the Computeraided Evaluation Tool. PROKUS. Institut für Arbeitswissenschaft und Betriebsorganisation Alemania, 1-17.

Giraldo, J. a. (2011). Método para la evaluación integral de la usabilidad en sistemas e-learning. Revista Educacion en Ingenieria, 69-80.

Heck, P. \&. (2010). A software product certification model. Software Quality Journal, 0.1007/s 11219-009-9080-0, 37-55.

Juan-Miguel López Gil, C. N. (2010). Análisis de la arquitectura de webs mediante tests de estrés de navegación. El profesional de la información, 359-367.

Kan, S. (2002). Metrics and models in software quality engineering. Addison-Wesley Longman Publishing Co.

Macleod, M., \& Rengger, R. (1998). The Development of DRUM: A Software Tool for Video-assisted Usability Evaluation. National Physical Laboratory DITC HCI Group.

Macho, D. G. (2013). La calidad de una página web como herramienta de comunicación. Estudios sobre el mensaje periodístico, 253-261. doi:https://doi.org/10.5209/rev_ESMP.2013.v1 9.42032
Martínez, J. G. (20 of 09 2011). Evaluación de la usabilidad de un sitio web educativo y de promoción de la salud en el contexto universitario.

1-17. doi:https://doi.org/10.21556/edutec.2011.37.39 3

Mohd Naz'ri Mahrin, P. S. (2009). Selecting Usability Evaluation Methods for Software Process Descriptions. 16th Asia-Pacific Software Engineering Conference (APSEC 2009), 523-529.

Nielsen, J. (1994). Usability Enginering. Boston: Morgan Kaufmann.

Scolari, C. A. (2001). hacia una sociosemiótica de las interacciones digitales. Quaderns de comunicació i cultura, 255-257.

Standardization. (August 26, 2020). I.O. ISO 25000 Calidad del producto Software. Obtenido de http://iso25000.com/

Villegas, M. H. (2009). Implementación de un ambiente virtual colaborativo - especificación de un metamodelo de usabilidad. Revista Ingeniería e investigación, 7 